\title{
Mechanisms of zidovudine resistance in bacteria
}

\author{
C. S. LEWIN, RUTH A. ALLEN and S. G. B. AMYES \\ Department of Bacteriology, University of Edinburgh Medical School, Teviot Place, Edinburgh EH8 9AG
}

\begin{abstract}
Summary. Unlike their parent strains, zidovudine-resistant derivatives of Escherichia coli KL16 and Salmonella typhimurium NCTC 5710 were found to be incapable of incorporating radiolabelled thymidine into their chromosomal DNA. Since incorporation was still prevented in the presence of EDTA, resistance to zidovudine was not associated with a permeability barrier, but appeared to result from the loss of thymidine kinase activity, required for the phosphorylation of zidovudine. Pseudomonas aeruginosa, which is intrinsically zidovudine-resistant, was also shown to be incapable of incorporating thymidine into its DNA, but Staphylococcus epidermidis SK360 and Staph. aureus E3T, which are also intrinsically zidovudine-resistant, possessed thymidine kinase activity. This suggests that two distinct mechanisms of resistance to zidovudine exist in bacteria. Zidovudine resistance did not appear to confer resistance to other antibacterial agents.
\end{abstract}

\section{Introduction}

Zidovudine is a thymidine analogue in which an azido group is substituted for the $3^{\prime}$-hydroxy group. It is active against human immunodeficiency virus (HIV) and is useful in the treatment of acquired immune deficiency syndrome (AIDS). ${ }^{1,2}$ Zidovudine also displays antibacterial activity against Enterobacteriaceae but not against Pseudomonas aeruginosa or staphylococci, which are intrinsically resistant to the drug (MICs $>500 \mathrm{mg} / \mathrm{L})^{3,4}$ Both the antiviral and antibacterial activities of zidovudine are thought to be derived from the ability of the compound to act as a chain terminator after incorporation into viral or bacterial DNA. The azido group makes the formation of subsequent $5^{\prime}$ 3 ' phosphodiester linkages impossible. ${ }^{1,5}$

Escherichia coli and Salmonella typhimurium develop stable high-level zidovudine resistance after short-term exposure to the drug in vitro at concentrations up to 100 MIC. $^{6}$ The mechanism of zidovudine resistance appears to involve the loss of thymidine kinase activity which is required to convert zidovudine to its active triphosphate form. ${ }^{3,6}$ This can be shown by the inability of thymidine to antagonise the action of trimethoprim in zidovudine-resistant mutants. ${ }^{6}$ Thymidine normally confers resistance to trimethoprim as the dihydrofolate reductase pathway can be bypassed, but this can happen only if the bacterium possesses thymidine kinase. ${ }^{8}$

Received 16 May 1990; revised version accepted 21 June 1990.
This is only indirect evidence of thymidine kinase activity. Measuring the amount of radiolabelled thymidine incorporated into bacterial chromosomal DNA provides a direct method of assaying thymidine kinase activity as this enzyme is required to convert thymidine to thymidine monophosphate (fig. 1). ${ }^{8}$ In this investigation we studied the incorporation of radiolabelled thymidine into the DNA of $E$. coli KL16, $S$. typhimurium NCTC 5710 and zidovudine-resistant derivatives of these two strains, as well as $P$. aeruginosa and staphylococci, which are intrinsically resistant to the drug.

\section{Materials and methods}

\section{Antimicrobial agents}

Ampicillin (Beecham, UK), ciprofloxacin (Bayer, UK), gentamicin (Roussel, UK), tetracycline hydrochloride (Lederle, UK), trimethoprim lactate and zidovudine (Wellcome, UK) were dissolved in sterile distilled water. Lomefloxacin (Searle, UK) and ofloxacin (Hoechst, UK) were dissolved in $0.5 \mathrm{M} \mathrm{NaOH}$ and then made up to the appropriate concentration with sterile distilled water.

\section{Bacterial strains}

E. coli KL16, ${ }^{9}$ S. typhimurium NCTC 5710, Staphylococcus aureus E3T, ${ }^{10}$ Staph. epidermidis SK $360^{11}$ and $P$. aeruginosa CP (from Professor J. T. Smith) were used in this investigation. Zidovudine-resistant derivatives of $E$. coli KL16 and $S$. typhimurium NCTC 5710 were prepared by plating serial dilutions of bacteria that had been 
exposed to zidovudine $100 \mathrm{mg} / \mathrm{L}$, in nutrient broth overnight at $37^{\circ} \mathrm{C}$, on to nutrient agar containing zidovudine $100 \mathrm{mg} / \mathrm{L}$.

\section{Minimum inhibitory concentration determinations}

MICs were determined by the agar incorporation method on Nutrient Agar (Oxoid) or, in the case of trimethoprim, on Iso-Sensitest Agar (Oxoid) with an arithmetic dilution scheme that followed the progression: $1,1 \cdot 5,2,3,4,5$ and $7 \cdot 5$. An inoculum of $10^{4} \mathrm{cfu}$ was used and the MIC was taken as the lowest concentration that inhibited visible growth after overnight incubation of the plates at $37^{\circ} \mathrm{C}$.

\section{Incorporation of thymidine into bacterial DNA}

Incorporation of thymidine into bacterial DNA was estimated by a modified version of the method of Schubach et al.$^{12}$ Bacteria were grown in $100 \mathrm{ml}$ of DM medium, ${ }^{13}$ containing glucose $0 \cdot 28 \%$, inoculated with $10 \mathrm{ml}$ of an overnight culture and shaken for $3 \mathrm{~h}$ at $37^{\circ} \mathrm{C}$. The cells were then harvested by centrifugation for $35 \mathrm{~min}$ at $6000 \mathrm{~g}$. The supernate was discarded and the pellet was resuspended in DM broth containing deoxyadenosine $200 \mathrm{mg} / \mathrm{L}$ and methyl ${ }^{3} \mathrm{H}$ thymidine (TRK 120 Amersham, UK) $2 \mu \mathrm{Ci} / \mathrm{ml}$; this suspension was then shaken for a further $2 \mathrm{~h}$ at $37^{\circ} \mathrm{C}$. After incubation, the culture was cooled for $10 \mathrm{~min}$ in ice; $1 \mathrm{ml}$ of trichloroacetic acid (TCA) $50 \%$ and $1 \mathrm{ml}$ of a thymidine $1 \mathrm{mg} / \mathrm{L}$ solution were then added and a precipitate was allowed to form at $0^{\circ} \mathrm{C}$ for $60 \mathrm{~min}$. Duplicate samples of 1 in 10 dilutions of the precipitate were filtered through a glass fibre filter disk (Whatmann, UK). The filter disk was then washed with $5 \mathrm{ml}$ of cold TCA $1 \%$ followed by $15 \mathrm{ml}$ of boiling, distilled water. This was followed by washes with $5 \mathrm{ml}$ of $\mathrm{NaCl} 5 \%$ and $10 \mathrm{ml}$ of acetic acid $5 \%$. The filter disks were then dried overnight in a desiccator and the radioactivity was determined in a Packard Tri Carb liquid scintillation counter. The scintillation fluid used was OptiScint "Safe” (LKB).

\section{Results and discussion}

In contrast to their respective parent strains, all nine zidovudine-resistant derivatives of $S$. typhimurium NCTC 5710 and $E$. coli KL16 (MICs of zidovudine $>500 \mathrm{mg} / \mathrm{L}$ ) were unable to grow on Iso-Sensitest agar containing thymidine $10 \mathrm{mg} / \mathrm{L}$ and trimethoprim $10 \mathrm{mg} / \mathrm{L}$ (table I). This result suggests that the resistant variants had lost thymidine kinase activity, as when their dihydrofolate reductase pathway was blocked by trimethoprim they were unable to use the alternative thymidine pathway to synthesise thymidine monophosphate (fig. 1). In contrast, Staph. aureus E3T and Staph. epidermidis SK 360, which were resistant to zidovudine (MICs $>500 \mathrm{mg} / \mathrm{L}$ ), were able to grow on IsoSensitest agar containing thymidine $10 \mathrm{mg} / \mathrm{L}$ and trimethoprim $10 \mathrm{mg} / \mathrm{L}$, although both strains were susceptible to trimethoprim (table I). This suggests that the intrinsic zidovudine resistance of the staphylococci is not related to a lack of thymidine kinase activity as both strains were able to use thymidine in the medium to antagonise trimethoprim action.

The ability of zidovudine-resistant Enterobacteriaceae to grow on Iso-Sensitest agar containing

Table I. Growth of bacteria on Iso-Sensitest agar containing trimethoprim alone or in combination with thymidine

\begin{tabular}{|c|c|c|c|c|}
\hline Strain & No drug & $\mathrm{Tp}(10 \mathrm{mg} / \mathrm{l})$ & $\begin{array}{c}\mathrm{Tp}(10 \mathrm{mg} / \mathrm{l})+ \\
\text { Thy }(10 \mathrm{mg} / \mathrm{l})\end{array}$ & $\begin{array}{c}\text { Thymidine } \\
\text { kinase } \\
\text { activity }\end{array}$ \\
\hline E. coli KL16 & + & - & + & + \\
\hline E. coli KL16RA30 & + & - & - & - \\
\hline E. coli KL16RA31 & + & - & - & - \\
\hline E. coli KL16RA33 & + & - & - & - \\
\hline E. coli KL16RA35 & + & - & - & - \\
\hline S. typhimurium NCTC 5710 & + & - & + & + \\
\hline S. typhimurium $5710 \mathrm{RA} 36$ & + & - & - & - \\
\hline S. typhimurium 5710 RA 37 & + & - & - & - \\
\hline S. typhimurium $5710 \mathrm{RA} 39$ & + & - & - & - \\
\hline S. typhimurium 5710RA40 & + & - & - & - \\
\hline S. typhimurium 5710RA41 & + & - & - & - \\
\hline Staph. aureus E3T & + & - & + & + \\
\hline Staph. epidermidis SK 360 & + & - & + & + \\
\hline
\end{tabular}

Tp, trimethoprim; Thy, thymidine; +, growth; - , no growth (after overnight incubation at $37^{\circ} \mathrm{C}$ ).

All strains grew on Iso-Sensitest agar containing thymidine $10 \mathrm{mg} / \mathrm{L}$. 


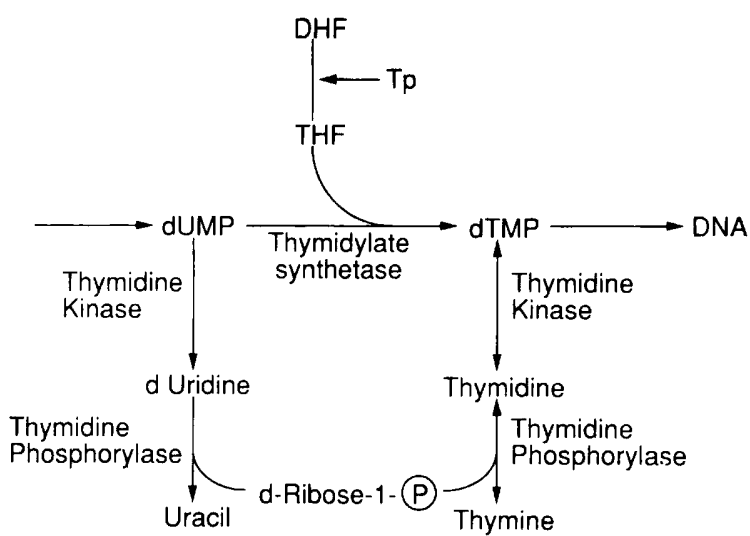

Fig. 1. Incorporation of thymidine derivatives in bacterial DNA. DHF, dihydrofolate reductase; $\mathrm{TFH}$, tetrahydrofolate; $\mathrm{Tp}$, trimethoprim.

thymidine and trimethoprim provides a rapid means of assessing whether resistance to the compound results from a loss of thymidine kinase activity.

E. coli KL16 was able to incorporate ${ }^{3} \mathrm{H}$ thymidine into its DNA indicating that this strain possesses thymidine kinase activity. Conversely, the counts of ${ }^{3} \mathrm{H}$ thymidine $/ 10^{8} \mathrm{cfu}$ were reduced 10-fold to 100 -fold in the three zidovudine-resistant derivatives of $E$. coli KL16 (table II) suggesting that the zidovudine-resistant derivatives are deficient in thymidine kinase activity. All three zidovudine-resistant $S$. typhimurium strains investigated were similarly unable to incorporate radiolabelled thymidine into their DNA. $P$. aeruginosa CP which, like all $P$. aeruginosa, is intrinsically resistant to zidovudine ( $\mathrm{MIC}>500 \mathrm{mg} / \mathrm{L}$ ), was also found to be incapable of incorporating radiolabelled thymidine into its DNA (table II). To exclude the possibility that the resistance could be conferred by an impermeability mechanism, the ability of the strains to incorporate ${ }^{3} \mathrm{H}$ thymidine in the presence of $0.3 \mathrm{~mm}$ EDTA (edetic acid) was examined. The uptake of ${ }^{3} \mathrm{H}$ thymidine by $E$. coli KL16 in DM containing $0.3 \mathrm{mM}$ EDTA was almost 10 -fold greater than the uptake in DM alone (table II) indicating an increase in permeability following EDTA treatment. In contrast, the presence of $0.3 \mathrm{mM}$ EDTA in the DM broth did not significantly increase the uptake of ${ }^{3} \mathrm{H}$ thymidine by either $E$. coli KL16RA35 or $P$. aeruginosa CP (table II) confirming that the inability of these strains to incorporate ${ }^{3} \mathrm{H}$ thymidine into their DNA derives from an absence of thymidine kinase activity rather than from a permeability barrier.

Both Staph. aureus E3T and Staph. epidermidis SK 360 were able to incorporate ${ }^{3} \mathrm{H}$ thymidine into their DNA (table II) in confirmation of the result obtained in experiments with trimethoprim and thymidine which indicated that the intrinsic zidovudine resistance in Staph. aureus E3T and Staph. epidermidis SK 360 did not result from a lack of thymidine kinase. EDTA could not be used to investigate impermeability as a possible cause of the lack of susceptibility to zidovudine in the staphylococci as this technique works only with gram-negative bacteria. Instead, the effect of zidovudine concentrations up to $100 \mathrm{mg} / \mathrm{L}$ on the incorporation of ${ }^{3} \mathrm{H}$ thymidine into bacterial DNA was determined. Reduction in the incorporation of ${ }^{3} \mathrm{H}$ thymidine into DNA by zidovudine would provide evidence that the drug was competing for the same uptake pathway as thymidine and,

Table II. Incorporation of ${ }^{3} \mathrm{H}$ thymidine into chromosomal DNA

\begin{tabular}{|c|c|c|c|}
\hline \multirow[b]{2}{*}{ Organism } & \multirow[b]{2}{*}{$\begin{array}{c}\text { MIC of zidovudine } \\
(\mathrm{mg} / \mathrm{L})\end{array}$} & \multicolumn{2}{|c|}{ Counts $/ 10^{8}$ bacteria } \\
\hline & & $\begin{array}{l}\text { without } \\
\text { EDTA }\end{array}$ & $\begin{array}{l}\text { with } \\
\text { EDTA }\end{array}$ \\
\hline E. coli KL16 & $0 \cdot 15$ & 3250 & 29510 \\
\hline E. coli KL16RA30 & $>500$ & 156 & NT \\
\hline E. coli KL16RA31 & $>500$ & 267 & NT \\
\hline E. coli KL16RA35 & $>500$ & 36 & 48 \\
\hline S. typhimurium NCTC 5710 & 1 & 4835 & NT \\
\hline S. typhimurium 5710RA37 & $>500$ & 49 & NT \\
\hline S. typhimurium $5710 \mathrm{RA} 39$ & $>500$ & 30 & NT \\
\hline S. typhimurium $5710 \mathrm{RA} 40$ & $>500$ & 23 & NT \\
\hline P. aeruginosa $\mathrm{CP}$ & $>500$ & 30 & 69 \\
\hline Staph. aureus E3T & $>500$ & 6038 & NT \\
\hline Staph. epidermidis SK 360 & $>500$ & 5285 & NT \\
\hline
\end{tabular}

NT, not tested. 
therefore, that impermeability was not the cause of the intrinsic resistance of the staphylococci to zidovudine.

High concentrations of zidovudine $(>10 \mathrm{mg} / \mathrm{L})$ reduced by $80-90 \%$ the uptake of radiolabelled thymidine by both strains of staphylococci (fig. 2). Therefore, impermeability does not appear to be the cause of the insusceptibility to zidovudine. The inhibition of the uptake of extracellular thymidine by zidovudine will not completely inhibit bacterial multiplication because the dihydrofolate reductase pathway can be used to provide thymidine monophosphate (fig. 1).

A possible explanation for the intrinsic resistance of the staphylococci to zidovudine is that the compound is not a substrate for either staphylococcal thymidine kinase or DNA polymerase III and, therefore, the drug is not incorporated into the staphylococcal DNA.

Possible cross-resistance to other antibacterial agents was also determined. The MICs of ciprofloxacin, lomefloxacin, ofloxacin, ampicillin, gentamicin, tetracycline and trimethoprim for the zidovudine-resistant strains were identical with those for their parent strains.

In conclusion there appear to be at least two distinct mechanisms of zidovudine resistance: one involves a lack of thymidine kinase activity; for the second, found in the staphylococci, the mechanism

\section{REFERENCES}

1. Mitsuya H, Weinhold KIJ, Furman PA et al. 3'-azido3'deoxythymidine (BW A509U): an antiviral agent that inhibits the infectivity and cytopathic effect of human T-lymphotrophic virus type III/lympadenopathy-associated virus in vitro. Proc Natl Acad Sci USA 1985; 82: 7096-7100.

2. Mitsuya H, Broder S. Strategies for antiviral therapy in AIDS. Nature 1987; 325: 773-778.

3. Elwell L.P, Ferone R, Freeman GA et al. Antibacterial activity and mechanism of action of $3^{\prime}$-azido- $3^{\prime}$ deoxythymidine (BW A509U). Antimicrob Agents Chemother 1987 ; 31 : 274-280.

4. Lewin CS, Amyes SGB. Conditions required for the antibacterial activity of zidovudine. Eur J Clin Microbiol Infect Dis 1989; 8: 737-741.

5. Hirsch MS. Azidothymidine. J Infect Dis 1988; 157: 427431.

6. Lewin CS, Allen R, Amyes SGB. Zidovudine-resistance in Salmonella typhimurium and Escherichia coli. J Antimicrob Chemother $1990 ; 25$ : 706-708.

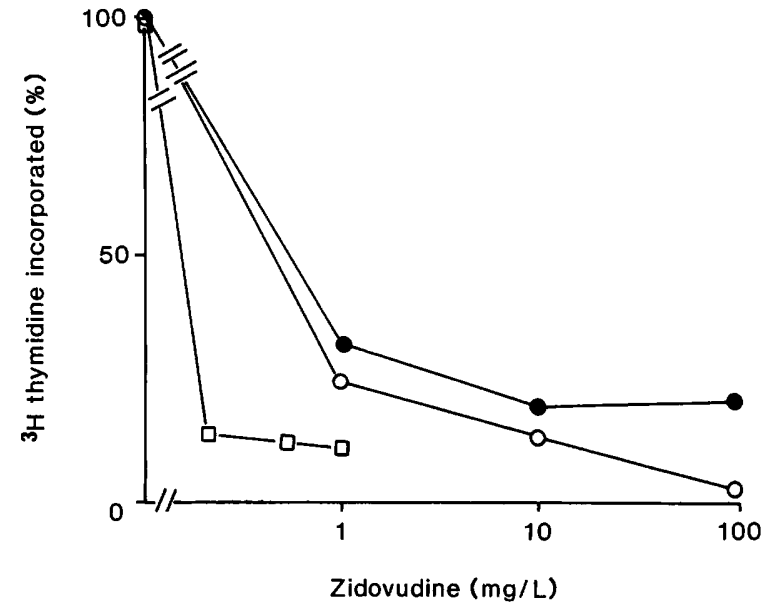

Fig. 2. Incorporation of ${ }^{3} \mathbf{H}$ thymidine by Staph. aureus E3T (-O), Staph. epidermidis SK 360 (O-O) and E. coli KL16 $(\square-\square)$ in the presence of zidovudine.

of resistance remains unknown except that it does not seem to result from an impermeability barrier. Neither type of resistance appears to affect the susceptibility of the bacteria to other antibacterial agents. This is significant as we have recently reported the isolation of zidovudine-resistant $E$. coli in AIDS patients. ${ }^{14}$

We thank the Scottish Home and Health Department for financial support of this work.

7. Koch AE, Burchall JJ. Reversal of antimicrobial activity of trimethoprim by thymidine in commercially prepared media. Appl Microbiol 1971; 22: 812-817.

8. Amyes SGB, Smith JT. Trimethoprim action and its analogy with thymine starvation. Antimicrob Agents Chemother $1974 ; 5: 169-178$.

9. Lewin CS, Smith JT. Bactericidal mechanisms of ofloxacin. $J$ Antimicrob Chemother $1988 ; 22$ : Suppl C: 1-8

10. Tennent JM, Young H-K, Lyon BR, Amyes SGB, Skurray RA. Trimethoprim-resistance determinants encoding a dihydrofolate reductase in clinical isolates of Staphylococcus aureus and coagulase-negative staphylococci. $J$ Med Microbiol 1988; 26: 67-73

11. Smith JT. Awakening the slumbering potential of the 4quinolone antibacterials. Pharm J 1984; 233: 299-305.

12. Schubach WH, Whitmer JD, Davern CI. Genetic control of DNA initiation in Escherichia coli. J Mol Biol 1973; 74: 205-221.

13. Davis BD, Mingioli ES. Mutants of Escherichia coli requiring methionine or vitamin $B_{12}$.J Bacteriol 1950; 60: 17-28.

14. Lewin CS, Paton R, Watt B, Amyes SGB. Isolation of zidovudine resistant Enterobacteriaceae from AIDS patients. FEMS Microbiol Lett 1990; 70: 141-144. 